\title{
PENGARUH DISIPLIN DAN MOTIVASI TERHADAP KINERJA KARYAWAN PT. BFI FINANCE INDONESIA TBK BSD - TANGERANG SELATAN
}

\author{
${ }^{1 *}$ Fahmi Susanti, ${ }^{2}$ Dicky Anggun Prasetya \\ Universitas Pamulang, Tangerang Selatan, Banten, Indonesia \\ *dosen02024@gmail.ac.id
}

\begin{abstract}
Abstrak
Penelitian ini bertujuan mengetahui pengaruh disiplin dan motivasi terhadap kinerja karyawan pada PT. BFI Finance Indonesia Tbk BSD - Tangerang Selatan. Metode penelitian ini menggunakan metode asosiatif kausal dengan teknik kuantitatif. Teknik sampling yang digunakan probabilty sampling menggunakan teknik sample jenuh. Dengan jumlah responden sebanyak 57 orang karyawan. Hasil penelitian disiplin dan motivasi berpengaruh signifikan terhadap kinerja karyawan dengan persamaan regresi $Y=8,386+0,449 X 1+0,355 X 2$. Nilai koefisien korelasi diperoleh sebesar 0,766 artinya variabel bebas dengan variabel terikat memiliki tingkat hubungan yang kuat, koefisien determinasi sebesar $58,7 \%$. Uji hipotesis diperoleh nilai F hitung $>\mathrm{F}$ tabel atau $(38,418>2,780)$. Dengan demikian H0 $:$ p3 $=0$ ditolak dan Ha $:$ p3 $\neq 0$ diterima. Artinya terdapat pengaruh signifikan secara simultan antara disiplin dan motivasi terhadap kinerja karyawan PT BFI Finance Indonesia Tbk. BSD - Tangerang Selatan.
\end{abstract}

Kata Kunci: Disiplin, Motivasi, Kinerja Karyawan

\section{Abstract}

This study aims to determine the effect of discipline and motivation on employee performance at PT. BFI Finance Indonesia Tbk BSD - South Tangerang. This research method uses causal associative method with quantitative techniques. The sampling technique used is probability sampling using a saturated sample technique. With the number of respondents as many as 57 employees. The results of the study of discipline and motivation have a significant effect on employee performance with the regression equation $Y=8.386+0.449 X 1+0.355 X 2$. The value of the correlation coefficient is 0.766 , meaning that the independent variable and the dependent variable have a strong relationship, the coefficient of determination is 58.7\%. Hypothesis testing is obtained by the calculated F value $>$ F table or $(38.418>2.780)$. Thus $\mathrm{HO}: \mathrm{p3}=0$ is rejected and $\mathrm{Ha}: \mathrm{p3} 0$ is accepted. This means that there is a simultaneous significant influence between discipline and motivation on the performance of PT BFI Finance Indonesia Tbk employees. BSD - South Tangerang.

Keywords: Discipline, Motivation, Employee Performance

\section{PENDAHULUAN}

Kinerja karyawan secara umum adalah sebuah perwujudan kerja yang dilakukan oleh karyawan yang biasanya digunakan sebagai dasar atau acuan penilaian terhadap karyawan didalam suatu organisasi. Kinerja yang baik merupakan suatu langkah untuk menuju tercapainya tujuan organisasi oleh karena itu, kinerja juga merupakan sarana penentu dalam mencapai tujuan organisasi sehingga perlu diupayakan untuk meningkatkan kinerja karyawan. Setiap perusahaan dalam melakukan aktivitasnya pasti memiliki tujuan yang hendak dicapai, untuk mencapai atau mewujudkan tujuan tersebut setiap perusahaan harus pandai dalam memilih strategi, terutama adalah perencanaan sumber daya manusia yang pada intinya adalah terfokus pada langkahlangkah tertentu yang diambil oleh manajemen. Atas tersedianya tenaga kerja yang tetap untuk menempati jabatan serta waktu yang tepat dalam rangka pencapaian tujuan dan berbagai sasaran yang ditetapkan.

Manajemen adalah sebuah sistem dimana sistem ini yang mengatur segala bentuk aktivitas manusia, mulai dari perencanaan sampai akhir proses yang 
sudah dicapai. Menurut Mangkunegara (2014:2) "Manajemen Sumber Daya Manusia (SDM) adalah suatu perencanaan, pengorganisasian, pengkoordinasian, pelaksanaan dan pengawasan terhadap pengaduan, pengembangan, pemberian balas jasa, pengintegrasian, pemeliharaan dan pemisahan tenaga kerja dalam rangka mencapai tujuan organisasi." Yang menjadi unsur utama dari manajemen SDM yaitu manusia. Ini karena SDM berhubungan erat dengan kinerja manusia. Manajemen SDM akan behubungan dengan implementasi dan desain dari sistem perencanaan. Penyusunan dan pengembangan karyawan, evaluasi kerja, pengelolaan karier, kompensasi karyawan, serta hubungan baik antara ketenagakerjaan. Manajemen SDM akan melibatkan seluruh keputusan serta praktik manajemen. Tentunya ini akan mempengaruhi sumber daya manusia secara langsung. Oleh karena itu, perusahaan akan merasa beruntung jika menggaet manajerial yang cukup briliyan, yang akan melakukan manajemen dengan baik. Manajemen SDM menjadi penting dalam memanajemen tenaga kerja melalui proses pendayagunaan, pengaturan, pengurusan, pembinaan dan pengembangan unsur dari tenaga kerja. Manajemen dilakukan pada semua SDM, baik yang memiliki status buruh, karyawan, atau pegawai.

Disiplin dapat diterapkan dan dimulai dari lingkungan keluarga, lingkungan sekolah (tempat menuntut ilmu), lingkungan masyarakat, serta lingkungan pekerjaan. Disiplin merupakan pokok dasar masalah yang dihadapi oleh setiap karyawan. Dengan adanya disiplin yang tercermin dari setiap karyawan, berarti karyawan tersebut dapat mematuhi setiap peraturan yang berlaku di perusahaan tersebut. Hal ini juga sesuai dengan pendapat Sutrisno (2016:98) bahwa "disiplin sangat diperlukan untuk menunjang kelancaran segala aktifitas organisasi agar tujuan organisasi dapat dicapai secara maksimal. Disiplin kerja dapat dilihat sebagai sesuatu yang besar manfaatnya, baik bagi kepentingan organisasi maupun kepentingan pegawai."

Aspek kualitas kerja yang di hasilkan berikutnya adalah rapi dan terstruktur mengalami trend yang menurun dalam hal maksimal selama kurun waktu 3 tahun terakhir. Pada tahun 2017 aspek rapi dan terstruktur secara maksimal sebesar $67 \%$, sedangkan aspek rapi dan terstruktur secara tidak maksimal mencapai persentase sebesar 33\%. Pada tahun 2018 aspek rapi dan terstruktur secara maksimal sebesar $58 \%$, sedangkan aspek rapi dan terstruktur secara tidak maksimal mencapai persentase sebesar 42\%. Pada tahun 2019 aspek rapi dan terstruktur secara maksimal mencapai persentase sebesar 39\%, sedangkan aspek rapi dan terstruktur secara tidak maksimal mencapai persentase sebesar $61 \%$.

Penilaian kinerja yang terakhir adalah inisiatif karyawan dalam melaksanakan tugas dan tanggung jawabnya dimana aspek ini meliputi, kemampuan karyawan dalam menciptakan peluang dan mengatasi permasalahan tanpa adanya perintah mengalami hasil yang stagnan/relative dan tidak mengalami peningkatan atau penurunan dari segi maksimal maupun tidak maksimal dalam periode 3 tahun terakhir terhitung dari tahun 2017 sampai dengan tahun 2019. Pada tahun 2017 aspek menciptakan peluang secara maksimal mencapai 57\%, sedangkan menciptakan peluang secara tidak maksimal mencapai 43\%. Pada tahun 2018 aspek menciptakan peluang secara maksimal mencapai $57 \%$, sedangkan menciptakan peluang secara tidak maksimal mencapai $43 \%$. Pada tahun 2019 aspek menciptakan peluang secara maksimal mencapai 57\%, sedangkan menciptakan peluang secara tidak maksimal mencapai $43 \%$.

Aspek inisiatif karyawan berikutnya adalah mengatasi masalah tanpa adanya perintah dimana pada tahun 2017 aspek mengatasi masalah tanpa adanya perintah secara maksimal mengalami trend yang kurang baik dimana aspek ini hanya mencapai $42 \%$, sedangkan aspek mengatasi masalah tanpa adanya perintah secara tidak maksimal mencapai 58\%. Pada tahun 2018 aspek mengatasi masalah tanpa adanya 
perintah secara maksimal mengalami trend yang kurang baik dimana aspek ini hanya mencapai $47 \%$, sedangkan aspek mengatasi masalah tanpa adanya perintah secara tidak maksimal mencapai 53\%. Pada tahun 2019 aspek mengatasi masalah tanpa adanya perintah secara maksimal mengalami trend yang kurang baik dimana aspek ini hanya mencapai $47 \%$, sedangkan aspek mengatasi masalah tanpa adanya perintah secara tidak maksimal mencapai 53\%

Hal ini menunjukan bahwa tingkat kinerja yang dilakukan oleh karyawan PT. BFI Finance Indonesia Tbk BSD - Tangerang Selatan dirasa masih belum maksimal dan efektif dalam menjalankan pekerjaannya, dilihat dari masih terdapatnya persentase di bawah 50\% dalam hal bekerja secara maksimal, maka dari itu perlu diminimalisir sebaik mungkin hal - hal yang mempengaruhi dari kinerja karyawan itu sendiri.

Kinerja merupakan hasil akhir dari setiap proses pekerjaan yang dilakukan oleh setiap karyawan, fungsi dari kinerja ini sebagai tolak ukur penilaian hasil yang sebelumnya sudah menjadi acuan untuk dijadikan sebagai tujuan utama, dari data diatas adanya naik dan turun dari pencapaian target yang telah ditentukan oleh perusahaan setiap tahunnya, hal ini berarti tingkat kinerja yang dilakukan oleh karyawan dirasa masih belum maksimal dalam menjalankan pekerjaannya, maka dari itu perlu diminimalisir sebaik mungkin hal - hal yang mempengaruhi dari kinerja karyawan itu sendiri.

Dari hasil penelitian sementara yang penulis amati, kinerja karyawan sangatlah berpengaruh terhadap produktivitas perusahaan, terutama pada pencapaian target yang telah ditentukan oleh perusahaan, tentu hal ini yang seharusnya bisa dijadikan perhatian penting bagi para karyawan, dalam menjalankan pekerjannnya, beberapa faktor yang dapat mempengaruhi kinerja karyawan itu sendiri yakni, disiplin dan motivasi, dari kedua faktor tersebut, perusahaan juga harus bisa memberikan sanksi yang tegas kepada para karyawan, agar dapat lebih meningkatkan rasa kedisiplinan, dan selanjutnya pemberian motivasi, pemberian motivasi ini juga penting diberikan kepada para karyawan, karna dengan pemberian motivasi, karyawan akan merasa dirinya diperhatikan. Apabila kedua faktor ini bisa diperbaiki oleh perusahaan, tentunya akan memberikan dampak yang positif kepada kinerja karyawan tersebut, produktivitas perusahaan dapat meningkat, pencapaian target perusahaan dapat tercapai dengan baik dan tentunya bisa menjadi salah satu perusahaan yang mampu bersaing dalam dunia bisnis.

Berdasarkan penjelasan diatas, maka penulis tertarik untuk melakukan penelitian mengenai "Pengaruh Disiplin \& Motivasi Terhadap Kinerja Karyawan PT. BFI Finance Indonesia Tbk BSD - Tangerang Selatan".

\section{TINJAUAN PUSTAKA}

\section{Disiplin}

Menurut Sutrisno mendefinisikan "Disiplin kerja adalah perilaku seseorang yang sesuai dengan peraturan, prosedur kerja yang ada atau sikap dan tingkah laku serta perbuatan yang sesuai dengan peraturan dari organisasi baik tertulis maupun tidak tertulis". Dalam penelitian ini indikator yang digunakan meliputi: taat terhadap aturan waktu taat terhadap aturan organisasi, taat terhadap aturan perilaku dalam pekerjaan, taat terhadap peraturan lainnya.

\section{Motivasi}

Yang dimaksud disiplin kerja dalam penelitian ini adalah kesadaran dan kesediaan seseorang menaati semua peraturan perusahaan dan normanorma sosial yang berlaku. (Hasibuan, 2014:193). Adapun indikator yang digunakan meliputi: tujuan dan kemampuan, teladan pimpinan, balas jasa, keadilan, dan ketegasan.

\section{Kinerja}

Dalam penelitian ini yang dijadikan variabel dependen adalah kinerja karyawan yang diartikan sebagai hasil kerja seorang pekerja, sebuah 
proses manajemen atau suatu organisasi secara keseluruhan, dimana hasil kerja tersebut harus dapat ditunjukkan buktinya secara konkrit dan dapat diukur, dibandingkan dengan standar yang telah ditentukan. (Sedarmayanti, 2013:260). Adapun indikator yang digunakan meliputi: prestasi kerja, tanggung jawab, ketaatan, kejujuran, dan kerjasama.

\section{METODE}

Jenis penelitian yang dilakukan dalam penelitian ini adalah penelitian asosiatif kausal dengan teknik kuantitatif. Menurut Sugiyono (2016:55) "penelitian asosiatif kausal adalah penelitian yang bertujuan untuk mengetahui hubungan / pengaruh antara dua variabel atau lebih." Dengan penelitian ini maka akan dapat dibangun suatu teori yang berfungsi untuk menjelaskan, meramalkan dan mengontrol suatu gejala. Hubungan kausal merupakan hubungan yang sifatnya sebab-akibat, salah satu variabel (independen) mempengaruhi variabel yang lain (dependen). Penelitian asosiatif menggunakan teknik analisis kuantitatif atau statistik. Penelitian kuantitatif merupakan salah satu jenis penelitian yang spesifikasinya adalah sistematis, terencana, dan terstruktur dengan jelas sejak awal hingga pembuatan desain penelitiannya. Definisi lain menyebutkan penelitian kuantitatif adalah penelitian yang banyak menuntut penggunaan angka, mulai dari pengumpulan data, penafsiran terhadap data tersebut, serta penampilan dari hasilnya. Penelitian ini merupakan studi empiris yang bertujuan untuk menguji pengaruh disiplin dan motivasi terhadap kinerja karyawan.

\section{HASIL DAN PEMBAHASAN}

\section{Pengaruh Disiplin (X1) Terhadap Kinerja Karyawan (Y). \\ Berdasarkan hasil analisis,} diperoleh nilai persamaan regresi $\mathrm{Y}=$ $16,233+0,599 X_{1}$, koefisien korelasi sebesar 0,690 artinya kedua variabel mempunyai tingkat hubungan yang kuat. Nilai determinasi atau kontribusi pengaruh sebesar 0,475 atau sebesar $47,5 \%$ sedangkan sisanya sebesar $52,5 \%$ dipengaruhi oleh faktor lain. Uji hipotesis diperoleh nilai thitung $>\mathrm{t}$ tabel atau $(7,061>2,004)$. Dengan demikian $\mathrm{H}_{0}$ ditolak dan $\mathrm{H}_{1}$ diterima artinya terdapat pengaruh yang signifikan secara parsial antara disiplin terhadap kinerja karyawan pada PT. BFI Finance Indonesia Tbk BSD - Tangerang Selatan

2. Pengaruh Motivasi Terhadap Kinerja Karyawan

Berdasarkan hasil statistik, diperoleh nilai persamaan regresi $\mathrm{Y}=$ $16,954+0,578 \times 2$, koefisien korelasi sebesar 0,613 artinya kedua variabel mempunyai tingkat hubungan yang kuat. Nilai determinasi atau kontribusi pengaruh sebesar 0,376 atau sebesar $37,6 \%$ sedangkan sisanya sebesar $62,4 \%$ dipengaruhi oleh faktor lain. Uji hipotesis diperoleh nilai thitung $>\mathrm{t}$ tabel atau $(5,761>2,004)$. Dengan demikian $\mathrm{H} 0$ ditolak dan $\mathrm{H} 2$ diterima artinya terdapat pengaruh yang signifikan secara parsial antara motivasi terhadap kinerja karyawan pada PT. BFI Finance Indonesia Tbk BSD - Tangerang Selatan

3. Pengaruh Disiplin kerja dan Motivasi Terhadap Kinerja Karyawan

Berdasarkan hasil penelitian, menunjukkan bahwa disiplin (X1) dan motivasi (X2) berpengaruh positif terhadap kinerja karyawan dengan diperoleh persamaan regresi $\mathrm{Y}=8,386+$ $0,449 \times 1+0,355 \times 2$. Nilai koefisien korelasi atau tingkat pengaruh antara variabel bebas dengan variabel terikat diperoleh sebesar 0,766 artinya memiliki memiliki hubungan yang kuat. Nilai koefisien determinasi atau kontribusi pengaruh secara simutan sebesar 58,0\% sedangkan sisanya sebesar $42,0 \%$ dipengaruhi oleh faktor lain. Uji hipotesis diperoleh nilai $\mathrm{F}$ hitung $>$ Ftabel atau $(35,896>2,780)$. Dengan demikian $\mathrm{HO}$ ditolak dan $\mathrm{H} 3$ diterima. Artinya terdapat pengaruh yang signifikan secara simultan antara disiplin dan motivasi terhadap kinerja karyawan 
pada PT. BFI Finance Indonesia Tbk BSD - Tangerang Selatan.

\section{PENUTUP}

\section{Kesimpulan}

Berdasarkan uraian pada bab-bab sebelumnya, dan dari hasil analisis serta pembahasan mengenai pengaruh disiplin dan motivasi terhadap kinerja karyawan, sebagai berikut:

1. Disiplin berpengaruh signifikan terhadap kinerja karyawan dengan persamaan regresi $\mathrm{Y}=16,233+0,599 \mathrm{X}_{1}$ nila koefisien korelasi sebesar 0,690 artinya kedua variabel memiliki tingkat hubungan yang kuat dengan koefisien determinasi sebesar 47,5\% Uji hipotesis diperoleh $\mathrm{t}$ hitung $>\mathrm{t}$ tabel atau $(7,061>$ $2,004)$. Dengan demikian $\mathrm{H}_{0}: \mathrm{p}_{1}=0$ ditolak dan $\mathrm{H}_{\mathrm{a}}: \mathrm{p}_{1} \neq 0$ diterima artinya terdapat pengaruh signifikan antara disiplin terhadap kinerja karyawan di PT. BFI Finance Indonesia Tbk BSD Tangerang Selatan.

2. Motivasi berpengaruh signifikan terhadap kinerja karyawan dengan persamaan regresi $\mathrm{Y}=16,954+0,578 \mathrm{X}_{2}$ nilai koefisien korelasi sebesar 0,613 artinya kedua memiliki tingkat hubungan yang kuat dengan koefisien determinasi sebesar 37,6\%. Uji hipotesis diperoleh $\mathrm{t}$ hitung $>\mathrm{t}$ tabel atau $(5,761>$ $2,004)$. Dengan demikian $\mathrm{H}_{0}: \mathrm{p}_{2}=0$ ditolak dan $\mathrm{H}_{\mathrm{a}}: \mathrm{p}_{2} \neq 0$ diterima artinya terdapat pengaruh signifikan antara motivasi terhadap kinerja karyawan $(\mathrm{Y})$ di PT. BFI Finance Indonesia Tbk BSD Tangerang Selatan.

3. Disiplin dan motivasi berpengaruh signifikan terhadap kinerja karyawan dengan persamaan regresi $\mathrm{Y}=8,386+$ $0,449 X_{1}+0,355 X_{2}$. Nilai koefisien korelasi diperoleh sebesar 0,766 artinya variabel bebas dengan variabel terikat memiliki tingkat hubungan yang kuat dengan koefisien determinasi atau pengaruh secara simultan sebesar $58,7 \%$ sedangkan sisanya sebesar $41,3 \%$ dipengaruhi faktor lain. Uji hipotesis diperoleh nilai $F_{\text {hitung }}>$ $F$ tabel atau $(38,418>2,780)$. Dengan demikian $\mathrm{H}_{0}$ : $\mathrm{p}_{3}$ : 0 ditolak dan $\mathrm{H}_{\mathrm{a}}$ : $\mathrm{p}_{3} \neq 0$ diterima. Artinya terdapat pengaruh signifikan secara simultan antara disiplin dan motivasi terhadap kinerja karyawan di PT. BFI Finance Indonesia Tbk BSD Tangerang Selatan

\section{Saran}

1. Disiplin pernyataan yang paling lemah adalah nomor 10 yaitu perusahaan mendorong dan menekankan kepada setiap karyawan dalam perusahaan dapat bekerja sama dimana hanya mencapai rata-rata score terendah sebesar 3,54. PT. BFI Finance Indonesia Tbk BSD - Tangerang Selatan harus lebih baik lagi dalam rangka mendukung disiplin karyawan, perusahaan perlu mendorong adanya kerjasama antar karyawan dengan selalu memberikan perhatian dan meninjau pekerjaan karyawan bukan hanya saat karyawan menghadapi permasalahan saja tetapi perlu memeriksa kondisi anggota tim dan keadaan pekerjaan karyawan sesering mungkin, guna meningkatkan kinerja karyawan sehingga tujuan perusahaan dapat tercapai dengan baik.

2. Motivasi pernyataan yang paling lemah adalah nomor 8 yaitu. saya giat bekerja karena adanya kesempatan yang diberikan perusahaan untuk menduduki posisi tertentu dimana hanya mencapai rata-rata score terendah sebesar 3,70. PT. BFI Finance Indonesia Tbk BSD Tangerang Selatan harus lebih baik lagi dalam hal mendorong motivasi karyawan, perusahaan perlu memberikan posisi / kedudukan yang layak bagi karyawan perusahaan agar karyawan merasa termotivasi dan pencapaian target perusahaan akan tercapai.

3. Kinerja karyawan pernyataan yang paling lemah adalah nomor 3, yaitu saya mampu menyelesaikan hasil pekerjaan sesuai dengan harapan perusahaan dimana hanya mencapai rata-rata score terendah sebesar 3,68. PT. BFI Finance Indonesia Tbk BSD - Tangerang Selatan harus lebih baik lagi dalam hal meningkatkan kinerja karyawan, 
perusahaan perlu memasang new target atau target baru ketika karyawan mampu menyelesaikan pekerjaan nya serta diimbangi dengan peningkatan kompensasi yang terima oleh karyawan. Dengan target yang lebih tinggi dan pemberian kompenasasi yang tinggi pula kepada para karyawan, maka pencapaian target perusahaan dapat lebih di tingkatkan lagi.

\section{DAFTAR PUSTAKA}

Algifari, 2014. Analisis Regresi untuk Bisnis dan Ekonomi. Yogyakarta: BPFE.

Arianto, Nurmin \& Kurniawan, Hadi. (2020). Pengaruh Motivasi dan Lingkungan Kerja Terhadap Kinerja Karyawan. JENIUS (Jurnal Ilmiah Manajemen Sumber Daya Manusia), 3 (3), 2581-2769.

Birokrasi Indonesia. Surabaya: Aditya Media Publishing.

Effendy Aidil Amin, dan Fitria Juwita Ramadani. (2020). Pengaruh Gaya Kepemimpinan, Motivasi, Dan Disiplin Terhadap Kinerja Karyawan (Studi kasus PT. Modernland Reality, TBK). JENIUS (Jurnal Ilmiah Manajemen Sumber Daya Manusia), 3 (3), 2581-2769.

Fadli, Roni \& Hasanudin. (2020). Pengaruh Motivasi Kerja Terhadap Kinerja Karyawan Pada Yayasan Bait Qur'ani Ciputat. JENIUS. (Jurnal Ilmiah Manajemen Sumber Daya Manusia), 4 (1), 2581-2769.

Fahmi, Irham, 2016. Pengantar Manajemen Sumber Daya Manusia Konsep dan

Ghozali, Imam, 2017. Aplikasi Analisis Multivariate Dengan Program SPSS.

Edisi Kelima. Semarang: Badan Penerbit Undip.

Hasibuan, Malayu S.P, 2016. Manajemen Sumber Daya Manusia. Edisi Revisi. Jakarta: PT Bumi Aksara..

Istijanto, 2014. Riset Sumber Daya Manusia. Jakarta: PT. Gramedia Pustaka.

Kinerja. Jakarta: Mitra Wacana Media.

Mangkunegara, Anwar Prabu, 2014. Evaluasi Kinerja SDM. Cetakan ke tujuh, PT Refika Aditama: Bandung.
Muslimat, Ade \& Wahid Hariyaty Ab. (2021). Pengaruh Disiplin Kerja Terhadap Kinerja Karyawan PT. Pos Indonesia Kantor Cipondoh. JENIUS (Jurnal Ilmiah Manajemen Sumber Daya Manusia), 4 (2), 2581-2769.

Nurjaya, N., Affandi, A., Ilham, D., Jasmani, J., \& Sunarsi, D. (2021). Pengaruh Kompetensi Sumber Daya Manusia Dan Kemampuan Pemanfaatan Teknologi Terhadap Kinerja Aparatur Desa Pada Kantor Kepala Desa Di Kabupaten Gunungkidul, Yogyakarta. JENIUS (Jurnal Ilmiah Manajemen Sumber Daya Manusia), 4(3), 332-346.

Pratama, Angga. (2020). Pengaruh Disiplin Kerja Terhadap Kinerja Karyawan Pada PT. Wisata Angkasa Permai. Semarak, 3(2), 2662-3686.

Pratama, Angga. (2020). Pengaruh Kompensasi dan Disiplin Kerja Terhadap Kinerja Karyawan Pada PT. Pos Indonesia DC Ciputat. Disrupsi Bisnis, 3(2), 2621-797X.

Pusporini, Palupi J. (2018). Pengaruh Motivasi Kerja, Disiplin Kerja Dan Gaya Kepemimpinan Terhadap Kinerja Pegawai Di Lingkungan Rumah Sakit St. Carolus Summerecon Serpong. JENIUS (Jurnal Ilmiah Manajemen Sumber Daya Manusia), 1 (2), 2581-2769.

$R \mathcal{E} D$. Bandung: Alfabeta.

Rachman, 2017. Manajemen Sumber Daya Manusia Dalam Pendekatan TeoritisPraktis. Surabaya: Airlangga University Press.

Rialmi, Zackaria. (2020). Pengaruh Kedisiplinan Terhadap Kinerja Karyawan Pada PT. Bhakti Karya Distribusi Indonesia. JENIUS (Jurnal Ilmiah Manajemen Sumber Daya Manusia), 3 (3), 2581-2769.

Rivai, Veithzal, 2017. Manajemen Sumber Daya Manusia Untuk Perusahaan. Penerbit PT Raja Grafindo Persada, Jakarta, 2010.

Salim, A. O., \& Rawi, R. D. P. (2020). Pengaruh Jaminan Sosial Tenaga Kerja Terhadap Produktivitas Kerja 
Karyawan Pada PT Sumber Abadi Indonesia Cabang Kota Sorong Papua Barat. Jurnal Ilmiah Manajemen Emor (Ekonomi Manajemen Orientasi Riset), 4(1), 32-40.

Setiawan, Rio \& Susanti, Fahmi. (2019). Peran Manajemen Pembelajaran Dalam Meningkatkan Keterampilan Membaca Studi Kasus Pada BIMBA AIUEO Pamulang. INOVASI, 7 (2), 2581-2769.

Sinambela, Lijan Poltak, 2016. Manajemen Sumber Daya Manusia. Jakarta: Prenadamedia Group.

Singgih Santoso, 2015. Menguasai Statistik Multivariat. Jakarta: PT Elex Media Komputindo.

Sudjana, 2016. Manajemen dan Reformasi Pelayanan Publik dalam Konteks

Sugiyono, 2017. Metode Penelitian Administrasi dilengkapi dengan Metode

Suharsimi Arikunto, 2014. Prosedur Penelitian Suatu Pendekatan Praktek. Jakarta: Rineka Cipta.

Suryani, N Lilis. (2018). Pengaruh Gaya Kepemimpinan dan Motivasi Terhadap Kinerja Karyawan Pada PT. Boga Lestari Sentosa (Kenny Rogers Roasters Indonesia). JENIUS (Jurnal
Ilmiah Manajemen Sumber Daya Manusia), 2 (1), 2581-2769.

Susanti, Fahmi. (2018). Pengaruh Kepemimpinan Motivasi dan Iklim Organisasi Terhadap Kinerja Pegawai di Rumah Sakit Tangerang Selatan. KREATIF, 6 (1), 2339-0689.

Susanti, Fahmi. (2019). Pengaruh Budaya Organisasi dan Disiplin Kerja Terhadap Kinerja Karyawan Pada Klinik Tumbuh Kembang Yamet, Pamulang. JENIUS (Jurnal Ilmiah Manajemen Sumber Daya Manusia), 2 (2), 2581-2769.

Sutrisno, Edi, 2016. Manajemen Sumber Daya Manusia. Jakarta: Prenadamedia Group.

Suwanto. (2019). Pengaruh Disiplin Kerja dan Motivasi Kerja Terhadap Kinerja Karyawan Pada Rumah Sakit Umum Tangerang Selatan. JENIUS (Jurnal Ilmiah Manajemen Sumber Daya Manusia), 3 (1), 2581-2769.

Winardi, 2017. Manajemen. Bandung: Nardika Group.

Zameer, Ali, dkk. 2014. Pengaruh Disiplin Kerja Terhadap Kinerja Karyawan". Bandung: PT. Rekratama Putra Gegana. 